\title{
PENGGAMBARAN ALAM DALAM SASTRA JAWA KUNO DAN JAWA MODERN SEBAGAI PROMOSI WISATA
}

\author{
THE DESCRIPTIONS OF NATURE IN ANCIENT \\ JAVANESE LITERATURE AND MODERN JAVANESE \\ AS A TOURISM PROMOTION
}

\author{
Ratun Untoro \\ Balai Bahasa Daerah Istimewa Yogyakarta \\ Pos-el: ratunplus@gmail.com
}

\begin{abstract}
A bstract
Taurismpromtion is peformed in purpose It can benatural eent tostimlateinterest for tarists whoarepessing watching listening orreadingandfeelingnotin purpose It isassoiated tothenatural patrayal inliterary works The naturewas partrayed by thepotsor witers with pesconal fedingand theydond tend toreer totarismpurpose Even, somitimes thepots hidethebeautifil natureillustrationfrompublic Theyjust want toexpresstheir fedingand dond want peepletodbageefor thebesuty of naturethey partrayed Thoseproblemisfomilated in this rearch Natural condition appeared in literary works and it never beaddressed for taunsmpromtion Thedate of this rearchis dd andmodkn Javaneseliteraturetorevel houthepotspatrayed naturethroughages This reserch wasinitiatedfrom assumption that poess or wites peformed doservationabat natureanddiramstance, then they wereexpreseedin ther liteary works. This rearch proved that nature is still used by pots or wites to assist, complete, and givestary situation
\end{abstract}

Keyw ords: nature, aramstance, literature, poets/ wites

\begin{abstract}
Abstrak
Promosi wisata tidak selalu dalam bentuk kesengajaan. Ia bisa berupa keadaan alamiah yang tidak sengaja bisa menimbulkan daya tarik bagi wisatawan yang kebetulan melihat, mendengar, atau membaca serta merasakan. D emikian halnya dengan pengambaran alam yang terdapat dalam karya sastra. Ia dilukiskan oleh penyair atau pengarang dengan perasaan personal yang tidak harus selalu ingin ditujukan untuk tujuan wisata. Bahkan, kadangkala penyair ingin menyembunyikan keadaan alam yang dirasakan indah memesona itu dari masyarakat luas. Ia hanya ingin menuliskan perasaannya dan tidak perlu orang lain mencari kebenaran keadaan alam yang dilukiskannya. Hal-hal seperti itulah yang diungkap pada penelitian ini. Keadaan alam yang muncul dalam karya sastra dan tidak pernah ditujukan untuk tujuan promosi wisata. Data penelitian ini ialah karya sastra Jawa Kuno dan Jawa Modern untuk mengetahui bagaimana penyair atau pengarang melukiskan alam pada masing-masing zaman. Penelitian ini berawal dari asumsi bahwa penyair atau pengarang melakukan observasi terhadap alam dan lingkungannya kemudian muncul dalam karya-karyanya. Penelitian ini membuktikan bahwa alam sering digunakan oleh penyair atau pengarang untuk mengiringi, melengkapi, dan menambah suasana cerita.
\end{abstract}

Kata kunci: alam, lingkungan, sastra, penyair/ pengarang.

\section{PENDAHULUAN}

Jenis promosi wisata menggunakan media visual cukup menarik perhatian dan relatif efektif terutama untuk wisata alam dan budaya. Hal itu tidak dipungkiri mengingat media visual mampu menghadirkan wujud visual daerah tujuan wisata 
meskipun visualisasi tersebut terbatas pada subjektivitas penyaji. Subjektivitas penyaji visual tersebut diharapkan mampu menarik perhatian calon pengunjung dengan cara menyajikan bahan-bahan atau materi visual yang menarik. Tentu saja, sajian visual tersebut dibuat oleh profesional yang ahli di bidang visual dan paham mengenai materi yang berkaitan dengan promosi wisata. D engan demikian, keindahan alam atau materi objek wisata yang akan divisualkan mengandung unsur subjektiv yang telah disesuaikan dengan keinginan calon wisatawan. Subjektivitas tersebut telah digradasi oleh keinginan calon wisatawan. Hal itu berbeda dengan penggambaran keindahan alam yang tertuang dalam karya sastra. Santosa (1998:203) menyatakan bahwa ragam bahasa yang ditulis oleh ahli bidang pariwisata berbeda dengan bahasa sastrawan yang bukan ahli pariwisata. Bahasa sastrawan lebih bersifat personal, konotatif, menyatakan secara tidak langsung, dan menyimpang dari tata bahasa normatif. Namun, dalam makalahnya, Santosa (1998) menemukan beberapa puisi yang sengaja dibuat untuk kepentingan pariwisata atau puisi yang memuat informasi tentang objek-objek wisata di Indonesia, yaitu Potre Parivisata Indonesia dalamPuisi (editor Lazuardi Adi Sage, 1991), Pdret PanjangSeerangPengunjungPantai Sanur(A bdul Hadi W.M., 1975), Nyanyian Tanah Air, Ramadhan K.H. (1958), sajak Di Banjar Tunjuk Tabanan (Sapardi Djoko Damono, 1982), Piknik (Isma Sawitri, 1983), "Ziarah ke Slarong" (Abdul Rivai, 1934), dan Ulat dan Bardaudur (Slamet Muljana, 1951).

Selain Santosa (1998), beberapa makalah yang berkaitan dengan sastra dan pariwisata pernah ditulis oleh beberapa pakar dalam Seminar Nasional VIII Bahasadan SastraIndonesiayang diselenggarakan oleh Himpunan Pembina Bahasa Indonesia. Semarang: 21-23 Juli 1998. Setidaknya, ada tujuh makalah yang berkaitan dengan sastra dan pariwisata dari 33 makalah yang ada. Dua dari tujuh makalah tersebut, yaitu "Pemakaian Majas dalam Puisi Pariwisata" (Ovi Soviaty Rivay) dan "Promosi Kepariwisataan Indonesia dalam Puisi" (Puji Santosa) membahas puisi yang memang sengaja dibuat dalam rangka pariwisata.D ua makalah lainnya, "Budaya D aerah dalam Sastra Indonesia" (Imam Budi Utomo) dan "Sastra, Pengarang, dan Budaya" (Herry Mardianto) membahas budaya yang menjadi bahan inspirasi karya sastra. Satu makalah lain, "Kaba Minangkabau dan Wisata Budaya" (B.Trisman) menyarankan Kaba Minangkabau untuk dijadikan salah satu atraksi di objek wisata. Sementara itu, terdapat satu buku menarik berjudul Puisi Promosi Kepaniuisataan ditulis oleh Puji Santosa, dkk. (2013) membahas berbagai puisi di tanah air yang dikaitkan dengan promosi wisata daerah.

Buku dan beberapa makalah mengenai puisi dan pariwisata tersebut diciptakan mirip dengan saat profesional visual membuat visualisasi untuk mempromosikan objek wisata. Bedanya, penyair menggunakan kekuatan kata-kata. Namun, ada yang dilewatkan oleh para peneliti dan penulis makalah di atas, yaitu bahwa alam Indonesia dalam kurun waktu tertentu telah mengalami perubahan. Buku dan beberapa makalah di atas tidak menyebutkan adanya perubahan dan perbedaan keadaan alam (dan) budaya. Hal itu telah disadari oleh profesional promosi wisata melalui media visual yang senantiasa membuat visual terkini mengenai alam (dan budaya) Indonesia.

Berdasar pada latar belakang tersebut, pertanyaan penelitian pada makalah ini ialah bagaimana penggambaran alam dalam karya sastra dari waktu ke waktu? Untuk menjawab pertanyaan itu perlu dibatasi rentang waktu perubahan tersebut. Perubahan alam tentu tidak berlangsung cepat sehingga waktu yang ideal untuk mengetahui perubahan penggambaran alam dalam karya sastra Jawa berdasarkan genre sastra Kakawin (Jawa Kuno) dan Jawa Modern. Jawa Pertengahan sengaja tidak dijadikan sumber data karena lebih 
banyak memuat alam Bali (bandingkan Zoetmulder, 1985:33).

\section{PENGERTIAN ISTILAH DAN METODE PENELITIAN}

\subsection{Pengertian Istilah dan Data}

Pembagian sastra Jawa Kuno, sastra Jawa Pertengahan, dan sastraJawa Modern pada penelitian ini mengikuti Zoetmulder (1985:28-40). Sastra Jawa Kuno menggunakan metrum-metrum India yang disebut kakawin dan sastra Jawa Pertengahan disebut kidung dengan menggunakan metrum asli Jawa. Keduanya dapat dianggap sebagai sastra Jawa zaman dahulu yang berbeda dengan sastra pada Jawa Modern yang muncul awal abad ke-19 dengan pengaruh Islam-Arab. Pada dasarnya, Z oetmulder (1985) membedakan sastra Jawa Kuno-Pertengahan dengan sastra Jawa Modern adalah adanya pengaruh Islam atau bahasa Arab dengan yang tidak. Berdasar pada pembagian tersebut, penelitian ini membedakan sastra Jawa Kuno dan sastra Jawa Modem berdasarkan pada ada tidaknya pengaruh Islam atau bahasa Arab.

\subsection{Metode Penelitian}

Metode ialah cara sedangkan penelitian ialah kegiatan pengumpulan data. D engan demikian, metode penelitian ialah cara-cara yang digunakan untuk mengumpulkan data (Ahimsa-Putra, 2004). Metode penelitian yang digunakan pada penelitian ini ialah metode kualitatif dengan tujuan mencari data kualitatif yang berasal dari studi pustaka. D ata kualitatif tersebut dideskripsikan atau kemudian lazim disebut jenis penelitian deskriptif kualitatif. D eskripsi data mengenai keadaan alam dalam karya sastra (sastra Jawa Kuno dan sastra Jawa Modern) itu kemudian disandingkan dan dicari perbedaannya.

Agar data keduanya bisa dibandingkan/ dikomparasikan, pengambilan data pada masing- masing karya sastra sebaiknya mempunyai relasi yang sejajar. Penelitian seperti ini mempunyai paradigma komparatif-korelasional (A himsa-Putra, 2004). Agar pengambilan data tidak menyebar terlalu jauh dan tidak berkorelasi sehingga akhirnya sulit dikomparasikan, penelitian ini hanya akan mengambil data berupa penggambaran suasana lereng gunung, suasana pagi hari, dan suasana sore hari pada dua masa karya sastra (sastra Jawa Kuno dan sastra Jawa Modern). Sastra Jawa Kuno diwakili oleh beberapa teks yang telah dimuat dalam bukunya Zoetmulder (1985), sedangkan sastra Jawa Modern diambil dari naskah Kabar Ang்n karya Ki Padmasusastra (1843-1926) yang mendapat julukan Bapak Sastra Jawa Modern dan Serat Sasana Sastra(Jasawidagda, 1954).

\section{HASIL DAN PEMBAHASAN}

Penelitian ini merupakan pemikiran awal mengenai perubahan atau lebih tepatnya membandingan gambaran alam pada sastra Jawa K uno dan sastraJawa Modern. Teks mengenai alam yang tercantum di dalam karya sastra dianggap bisa memberi gambaran alam pada kenyataannya. Hal ini berdasar pada asumsi bahwa penggambaran alam pada karya sastra merupakan hasil observasi pengarang atas dunianya (bandingkan Z oetmulder, 1985:239). Meskipun demikian, selalu ada dialektika dan ketegangan antara kenyataan dalam karya sastra dan realitas dalam dunia nyata (bandingkan Wachid, 2005:73 dan Toer, 1984 tentang kebenaran hulu dan hilir).

\subsection{Penggambaran Alam pada Teks Jawa Kuno}

Penggambaran alam dalam sastra Jawa Kuno berikut diambil dari Z oetmulder (1985:238274).

\subsubsection{Lereng Gunung/ Jurang}

Di sebelah barat terdapat punggung-punggung bukit yang penuh dengan sawah-sawah, pe- 
matangnya kelihatan jelas dan tajam. Halamanhalaman saling berdekatan, rapi berderet, pohonpohon nyiur semuanya diselimuti kabut. Sayapsayap burung kuntul berkilauan ketika mereka terbang di atas, samar-samar kelihatan dari jauh di tengah-tengah awan, kemudian mereka lenyap, terlebur dalam kabut dan tidak kelihatan lagi (Sivaratrikalpa).

Perjalanan membawanya ke arah timur laut, tempat jurang-jurang memaparkan suatu pemandangan yang indah sekali bila kita melihat ke bawah; taman-taman pesanggrahan-pesanggrahan yang melingkar, candi-candi dan pertapaan seseorang, itu semua menimbulkan rasa kagumnya. Ladang-ladang luas terhampar, tersebar pada lereng gunung; sebatang sungai besar turun dari bukit dan mengairi tanaman itu (Sivaratrikalpa).

\subsubsection{Suasana Sore/ Senja}

Tistis hyangsurya pinten ghatita pitu, siremakmt kan sanghub avra "Saat itu kira-kira pukul tujuh'; hawa mulai menjadi sejuk dan matahari yang terselubung oleh kabut, kehilangan terangnya (Nagaraketagama).

Sesudah pukul tujuh (16.30) udara mulai menjadi sejuk. Inilah waktunya matahari yang sedang ngaso di atas sebuah punggung bukit atau yang menjelang menceburkan diri ke laut, telah kehilangan panasnya. Rupanya sinar-sinar melambaikan ucapan "selamat tinggal" yang terakhir. Segala suara mulai lenyap dan alam raya merasa bimbang, takut karena malam akan datang. Bunga Padma yang pagi hari mekar, menutup daundaunnya agar tepung sarinya terlindung baik-baik sambil menyediakan tempat tidur bagi kumbangkumbang. Awan-awan gelap berputar-putar bersama gemuruhnya guntur, memperingatkan manusia akan bahaya yang mungkin mengancam, supaya ia berjaga-jaga. Tetapi segala rasa takut lenyap, bilamana rembulan terbit dan mengusir kegelapan (Haniwangsa).

\subsubsection{Suasana Pagi}

Pukul tujuh sebelum matahari terbit, saat yang penuh nikmat, ketika kegelapan mulai lenyap dan udara masih segar, ketika angin sepoi-sepoi membawa keharuman bunga-bunga dan burung-burung mulai berkicau. Ia membayangkan, panghwab i skkar nikabab awang/ milu tang asckapada lawan pangulyat i sinir nikang alon(bagaimana alam terbangun bersama dengan bunga-bunga yang mekar semerbak, sedangkan cabang ascka merentangkan diri terayun oleh angin semilir (Bhomantaka)).

Bila para wanita ke luar dari rumah dan berdiri di pelataran, rambut mereka basah oleh embun, dan angin, bagaikan pelamar-pelamar yang cemburu, menarik perhatian mereka kepada bunga asama untuk hiasan sanggul, dan dengan demikian membunuh bunga itu saingan bagi sang angin. Pohon-pohon tidak lagi nampak seperti wayang, dan pohon cemara yang malam hari hanya berkeluh kesah, kini mulai kelihatan (Bharatayuddha).

\subsection{Penggambaran Suasana Alam dalam Sastra Jawa Modern}

\subsubsection{Lereng Gunung}

Dexi Angin-Angin, mrang marca nusup angayam alas, kandheg wonten ing eengeeengldengkdingreed Ambambi, ing ngiku wonten kajengjpun bendha doyongpinule ingmandra, shumpun ntup padhes an ingkang rembes angatk saking sukuning reed, stuningmandra patingkenrangsami tumali ingsda, puckipin sami marecth tees toyaripun dhawah ing sela tala ngantos angumit, kalempaking toya kuminik mili mangandhap anjog ing sumberan toganipun katingal wering kathah minanipun alitalit pating sini, SangRema kacaryan ningli kendl lenggah ing pepongling padhas skkunipun kdkdbok toja sarvi kapje-pjet wetiskaraossayah, danguSang Rema kendd wonten ing ngiku, angagas ldam 
pahaningsairaripun(KabarAngin Padmasusastra, 2011).

D ewi Angin-Angin berjalan seperti ayam hutan, terhenti di lereng gunung A mbambi, di sana terdapat kayu bendha yang tumbuh miring terlilit pohon beringin, sulur pohon beringin itu menutupi cadas yang mengeluarkan mata air yang merembes dari kaki gunung. Sulur itu menjulai membelit batu cadas hingga pucuknya meneteskan air yang akhirnya turun ke bawah menjadi kolam kecil dengan air jernih. Banyak ikan kecil berseliweran di sana, Sang D ewi duduk di tonjolan cadas sambil kakinya diayun-ayunkan bermain air sambil dipijit-pijitnya betisnya yang terasa lelah. Lama Sang D ewi berhenti di sana memikirkan perjalanan hidupnya (terjemahan oleh Ratun Untoro).

\subsubsection{Suasana Sore/ Senja}

Ing nalika samanten wani asar andhap langit sish kilen katingal endah, sunaring surya amjudaken reupen manami-vami: abrit, jen, ïem nungu maya maya, tempurtumempur asambt-sumambt. sakehap cantos reupen, boten kirang anggandkaken, sanding surya sumamburat mingcgh lan pencar ing sakiwa tengripun, amarg pancer prenahing surya kalingan ingmeg pthak. Sakedhap malih surya sampun beten katingll, ingsemusampund umg tanceping ckkrawala, kasanbuh saya mindhak kandding mea, sanalika ingjacad pindha padhang tanpa suryaWonten kont maburijen dpantilarkancaripun klepe:klepertanpa suarter damil tumauungemanah Anginmiddalon, dangrdangusaya mindhak sumilitipunnrajangtanem ingsabinipun kaki tani, dbahalenbak-lenbak pincha toga seganten katempuh ing anginIng sadanguipun, Pak Gununamngtansahkendd nadeyjegregkebdkan ing raos ayem tertrem kepranan dhateng gumdaring jagad raya (Serat Sasana Sastra, Jasawidagda, 1954).

Ketika saat azan salat Asar di bawah langit sebelah barat terlihat indah, sinar mentari memancarkan berbagai warna: merah, kuning, hijau, ungu saling bertemu bersahutan. Tidak lama kemudian berganti rupa sungguh menakjubkan. Sinar mentari semburat naik memancarkan cahaya ke selilingnya tertutup oleh mega yang semakin tebal sehingga dunia sepertinya terang meski tanpa mentari. Ada burung kuntul terbang sendirian ditinggal kelompoknya, terbang tanpa suara melangutkan hati. Angin semilir perlahan, lama-kelamaan tiupannya semakin kencang menabrak tanaman di persawahan petani hingga bergerak seperti ombak di lautan terkena angin. Selama itu, Pak Guru hanya termenung berdiri penuh rasa tenteram terpesona oleh indahnyajagad raya (terjemahan Ratun Untoro).

\subsubsection{Suasana Pagi}

Esunipun tang gregh dandan savatawis, nyangking tokenneebl; ingjawi taksh renengreneng ingterling wean, langit ingkang calak watesing bum, keingal arjirbabak abit tandhayen surya badhemethe.Witwitan ingpakampungan darengkatingal vaminingron lan skkaripun kajawi namung ngegemeng cemeng tumemple inglangtsampunsumadabit vaminipun, katingal ctha kadbs canbar wenangunan Wonten wit kilapamnggil darakipuntumbsorsengklehtumdung pangaos beten kawava nyangġ janjanggn ingkang mbiyt uchipun Ewodkeing tenghttenggh wonten barak noadeg jegey patutipun janur wivit meegr, manging methukaken pletheking surya, kadbs mancayubagja undunipun sang sitaresmi kadhesk sangbagaskara (Seat Sasana Sastra Jasawidagda, 1954).

Akhirnya terbangun dan merias diri sebentar, membawa tongkat keluar. Di luar masih remangremang. Di sisi timur, langit di ufuk timur terlihat memerah pertanda mentari hendak muncul. Pepohonan di perkampungan belum terlihat warna daunnya, terlihat seperti lukisan. Ada pohon kelapa dengan pelepah turun berayun-ayun di batangnya, seperti tidak kuasa menahan buah kelapa yang menggerombol. Sementara itu, di tengahtengahnya terdapat dahan yang berdiri tegak, rupanyajanur yang baru mulai mekar, menyambut mentari, seperti bahagia menyambut datangnya mentari yang menggeser malam(terjemahan Ratun Untoro). 
Suasana pegunungan pada teks sastra Jawa Kuno dan Jawa Modern di atas terlihat bahwa keadaan alam Nusantara khas daerah tropis yang dideskripsikan secara detil sehingga seolah-olah pembaca bisa melihat suasana tersebut. Suasana pegunungan pada teks Jawa K uno di atas melukiskan keadaan secara umum seperti potret dari angkasa sedangkan pada teks Jawa modern di atas dilukiskan secara detil bahkan hanya menceritakan tetesan air dari sulur pohon beringin yang melilit sebuah batang kayu bendha. Penggambaran suasana gunung secara umum pada teks Jawa Kuno dan menjadi gambaran khusus pada teks Jawa modern tersebut layaknya potret dari kamera drone yang kemudian di-zoom Kedua teks saling mendukung suasana dan penggambarannya tidak bertentangan. Padahal, kedua teks di atas berselisih waktu lebih dari 7 abad. Hal itu berbeda dengan penggambaran suasana senja pada kedua teks di atas sama-sama menggambarkan suasana awan dan langit di senja hari. Keduanya mengagumi sinar mentari sore yang tidak jauh berbeda keadaannya meski kedua teks ini "tidak saling mengenal". Teks penggambaran sore hari pada Jawa Modern memuat burung kuntul yang juga digambarkan pada teks Jawa Kuno di lereng gunung. Burung ini merupakan khas Jawa (setidaknya pada penyebutan kuntul) yang rupanya menjadi daya pikat para penyair sejak Jawa Kuno hingga Jawa Modern bersamaan dengan penggambaran yang sama pada sawah dan ladang. D emikian halnya suasana pagi hari yang digambarkan pada teks Jawa Kuno dan teks Jawa Modern tidak begitu berbeda. Kedua teks mempunyai daya imaji yang sama saat menggambarkan keremangan. Pada teks Jawa Kuno keremangan diibaratkan seperti wayang yang diketahui sebagai bayangan hitam di balik kelir, sedangkan pada teks Jawa Modern keremangan diibaratkan seperti lukisan yang belum terlihat warnanya (siluet).
Kemiripan penggambaran alam pada dua teks yang mempunyai rentang waktu beradad-abad itu menunjukkan bahwa keadaan alam Nusantara atau Indonesia tidak banyak berubah. Setidaknya, sejak Jawa Kuno hingga Jawa Modern, pengarang mempunyai konsep lukisan alam Indonesia seperti itu. Hal ini menjadi menarik tatkala disandingkan dengan teks yang memuat penggambaran alam di belahan dunia di luar Nusantara yang bukan beriklim tropis.

\section{SIMPULAN}

Pengarang teks-teks sastra Jawa, baik Jawa Kuno maupun Jawa Modern, mengungkap alam Nusantara sebagai bagian menegaskan suasana cerita yang berpijak pada kebenaran hulu. D engan demikian, meskipun isi cerita berupa fiksi, keadaan alam yang digambarkan bisa dipercaya kebenarannya. Penggambaran itu memang khas alam tropis dan khas Nusantara meskipun tidak semua cerita asli Nusantara. Penggambaran alam yang demikian detail dan indah secara tidak langsung turut menawarkan kecantikan alam tropis Indonesia sebagai daerah tujuan wisata yang layak dikunjungi dan dinikmati di antara tawaran hiruk pikuk dunia modern lainnya. Bahkan sebenarnya, membaca karya sastra Jawa merupakan bentuk wisata alam dengan cara yang berbeda.

\section{DAFTAR PUSTAKA}

Ahimsa-Putra, H. S. 2004. "Paradigma, Teori, dan Metode". Makalah. Padang: FISIP Universitas Andalas.

Jasawidadga. 1954. Sasana Sastra. Yogyakarta: D widaja.

Mardianto, Herry. 1998. "Sastra, Pengarang, dan Budaya"makalah Seminar Nasional VIII Bahasa dan Sastra Indonesia yang diselenggarakan oleh Himpunan Pembina 
Bahasa Indonesia. Semarang: 21-23 Juli Toer, Pramoedya Ananta. 1984. "Perburuan dan 1998. G erilja” dalam Proses Kreatif, Mengapa dan

Padmasusastra, Ki. 2011. SeratKabar Angin Bagaimana Saya Mengarang jilid II, ed. Terjemahan Riyadi Djaka Lelono, dkk. Surakarta: Yayasan Sastra Lestari.

Rivay, Ovi Soviaty. 1998 "Pemakaian Majas dalam Puisi Pariwisata" makalah Seminar Nasional VIII Bahasa dan Sastra Indonesia yang diselenggarakan oleh Himpunan Pembina Bahasa Indonesia. Semarang: 21-23 Juli 1998.

Santosa, Puji. 1998. "Promosi Kepariwisataan Indonesia dalam Puisi" makalah Seminar Nasional VIII Bahasa dan Sastra Indonesia yang diselenggarakan oleh Himpunan Pembina Bahasa Indonesia. Semarang: 2123 Juli 1998hlm. 203-220.

Pamusuk Eneste. Jakarta: G ramedia:51- 70.

Trisman, B. 1998. "Kaba Minangkabau dan Wisata Budaya" makalah Seminar Nasional VIII Bahasa dan Sastra Indonesiayang diselenggarakanoleh Himpunan Pembina Bahasa Indonesia. Semarang: 21-23 Juli 1998.

Utomo, Imam Budi. 1998. “Budaya D aerah dalam Sastra Indonesia"makalah Seminar Nasional VIII Bahasa dan Sastra Indonesia yang diselenggarakan oleh Himpunan Pembina Bahasa Indonesia. Semarang: 21-23 Juli 1998.

Wachid, Abdul. 2005. Sastra Pencerahan Yogyakarta: Penerbit Saka.

Santosa, Puji, dkk. 2013. Puisi Promosi Keparinisata Z Z oetmulder. 1985. Kalangnan Sastra Jana Kumo an Yogyakarta: Elmatera Publishing.

Seayang Pandang Terjemahan Dick Hartoko cetakan kedua. Jakarta: Penerbit D jambatan. 
Kadera Bahasa, Volume 9, Nomor 2, Edisi Agustus 2017 